\title{
Back pain in pregnant women attending an antenatal clinic in KwaZulu-Natal, South Africa
}

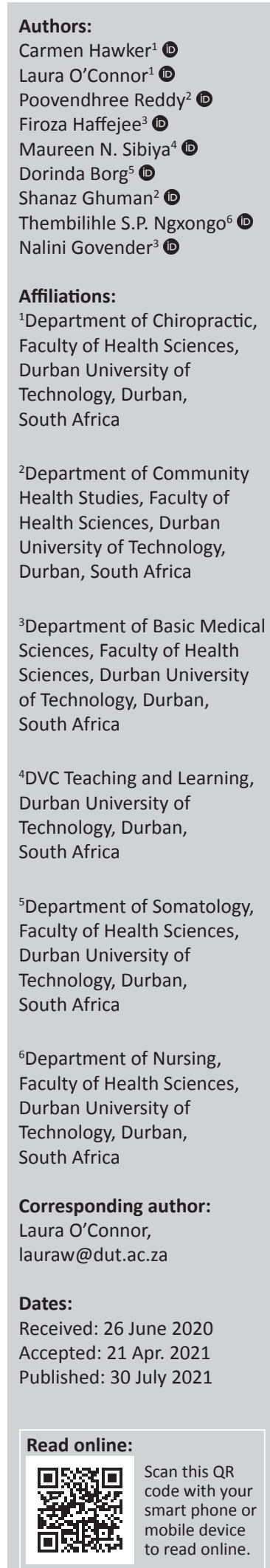

Background: Back pain is not uncommon in pregnant women, but it is often under-reported and can be disabling. International studies report a high prevalence of back pain, especially in the last trimester. Little is known about the prevalence of back pain in South African pregnant women.

Aim: To determine the prevalence and risk factors of back pain in a cohort of pregnant women

Setting: Public primary healthcare clinics and the eThekwini municipality of KwaZulu-Natal $(\mathrm{KZN})$, South Africa

Methods: A descriptive cohort design was used to survey pregnant women $(n=303)$ over the course of their pregnancy. Data were collected at the first antenatal visit and again in the third trimester. Participants gave consent and ethical clearance was obtained from an institutional research ethics committee, from the eThekwini Health District and KZN Provincial Department of Health.

Results: The respondents were young Black African women (mean age of $25.8( \pm 6.0)$, who were mostly unemployed (70.7\%), and resided in a resource poor setting. Back pain prevalence at the first antenatal visit and the third trimester was $12.4 \%(n=35)$ and $10.9 \%(n=5)$, respectively. This condition was associated with carrying water and residing in a hostel or an employee's property. Being single was associated with less risk for developing back pain.

Conclusion: The prevalence of back pain was low in this cohort of women, yet it resulted in a negative impact on the women's ability to cope with daily life.

Contribution: This is one of the first studies to describe back pain in a South African pregnant population.

Keywords: pregnancy; back pain; prevalence; South Africa; risk factors.

\section{Introduction}

Back pain is a significant health and economic problem affecting a large proportion of the population. It has a high disability rate with a severe impact on both the society and the individual (Docking et al. 2011). It is more common in women than men, attributable to hormones, pain sensitivity, as well as to social and psychological factors (Sencan et al. 2017). Back pain is one of the most common problems affecting women of childbearing age, and will affect half of all women at some stage during their pregnancy (Abebe et al. 2014; Usman et al. 2017). Many women will experience their first episode of back pain during pregnancy (Sencan et al. 2017) whilst some will experience persisting back pain post-partum (Abebe et al. 2014; Ayanniyi et al. 2006; Bergström, Persson \& Mogren 2016). For many women, there is an expectation that whilst being pregnant, life continues normally (Mota et al. 2015). Back pain in pregnancy has attracted the attention of researchers globally (Jimoh et al. 2013; Ramachandra et al. 2015) and according to Ayanniyi et al. (2006), there is no doubt that back pain is one of the most common complications associated with pregnancy and is often accepted as inevitable (Stuber \& Smith 2008).

The prevalence of pregnancy-related back pain is said to vary from $20 \%$ to $90 \%$ (Bergström et al. 2016; Usman et al. 2017). Factors such as previous back pain, strenuous work, back pain in previous pregnancies, increasing gravidity, as well as demographic and psycho-social factors (Charpentier et al. 2012) have been associated with increased risk. Most women fail to seek help

How to cite this article: Hawker, C., O'Connor, L., Reddy, P., Haffejee, F., Sibiya, M.N., Borg, D. et al., 2021, 'Back pain in pregnant women attending an antenatal clinic in KwaZulu-Natal, South Africa', Health SA Gesondheid 26(0), a1507. https://doi.org/10.4102/hsag.v26i0.1507 Copyright: @ 2021. The Authors. Licensee: AOSIS. This work is licensed under the Creative Commons Attribution License. 
until pain interferes with their daily lives (Sencan et al. 2017). Women are often encouraged to believe that their symptoms are temporary and self-limiting (Abebe et al. 2014; Ayanniyi et al. 2006), with their complaints often being dismissed as 'normal aches and pains of pregnancy' (Usman et al. 2017). Despite the high occurrence of pregnancy-related back pain, it remains a trivial aspect of pregnancy healthcare (Quaresma et al. 2010). The condition negatively impacts a woman's functioning and well-being, often resulting in sick leave, altered activities of daily living, deteriorating quality of life and ability to work (Mota et al. 2015). The characteristics of daily activities and their contribution to musculoskeletal (MSK) disorders, especially in pregnancy are not welldocumented (Beaucage-Gauvreau, Dumas \& Lawani 2012).

Women in developing countries are subject to intensive activities of daily living. West African women participate in laborious daily activities, ranging from farm work, drawing water from wells and carrying water for long distances, to commercial activities that require carrying heavy loads on their heads (Beaucage-Gauvreau et al. 2012). Intensive farm work and heavy weight-lifting were associated with the increased severity of back pain in Lesotho women (Worku 2000). South Africa has a diverse society, with various social, economic and environmental challenges. There is a high unemployment rate (29.8\%) (Statistics South Africa 2011) with a large percentage of female-headed households (Dungumaro 2008). Approximately, 84\% of the population depends on the public healthcare system, which is afflicted with human resource shortages and limited resources. This burden negatively impacts quality healthcare for the majority of the population (Benatar 2013). The current management of back pain at primary healthcare (PHC) level has been reported to be ineffective with little conformity to guidelines (Major-Helsloot et al. 2014). The 2000 Millennium Development Goals focus on maternal health, and integrated antenatal care has been posited as a mechanism to reach this target (Fowkes et al. 2016). In a country where the burden of infectious disease outweighs that of non-communicable disorder, there is often little focus on the latter. International literature on the effects of back pain in pregnancy is well established, and has attracted much attention. Moreover, limited data exist on the impact of back pain in pregnant women in developing countries (Charpentier et al. 2012), including South Africa. In light of this and the unique context of South Africa, the current study aimed to provide a description of back pain experienced by a cohort of pregnant women residing in a resource poor setting.

\section{Research methods and design Study design}

A descriptive cohort design was used to survey pregnant women $(n=303)$, with the aim to determine back pain characteristics, over the course of their pregnancy. Data were collected at the first antenatal visit and again in the third trimester. The study was conducted between October 2015 and October 2016.

\section{Study location}

This study was conducted at the antenatal clinic (ANC) in a PHC, in Umkhumbane, eThekwini District Municipality, KZN. There are 16 beds in a Medical Outpatient Unit run by the Provincial and eThekwini Municipality.

\section{Study population}

Women presenting at the clinic for their first ANC visit were invited by a trained research nurse, who was fluent in isi-Zulu and English, to participate in the survey. Informed consent was obtained prior to enrolment. All willing participants ( $n=303)$ completed the surveys, either in isi-Zulu or English, whilst they waited for their appointment at the clinic.

\section{Sources of data}

At the first antenatal visit, data were collected using the patients' clinical records, a socio-demographic questionnaire (developed by Napier et al. [2009]) and an epidemiological questionnaire. Information obtained from the patients' clinical records included height, weight and HIV status. The socio-demographic questionnaire provided data such as demographic characteristics, place of residence, accommodation, employment type and status and education level. The epidemiological questionnaire collected MSK data related to back pain prior to and during pregnancy. The questionnaires were designed by similar studies (Kristiansson, Svärdsudd \& Von Schoultz 1996; Skaggs et al. 2007); the modified Nordic Pain Questionnaire (Crawford 2007) and the Bournemouth pain questionnaire (BQ)(Bolton \& Breen 1999). Additional items added to the modified Nordic Pain Questionnaire included 'when did the pain start?', 'is your pain: mild, moderate or severe', 'has your pain interfered with your ability to perform your daily activities, such as gardening, house work, etc.' and 'has the pain affected your ability to work?'. The questionnaire was assessed for content and face validity through an expert group discussion and pilot tested for suitability for the target population. It was re-administered at the third trimester, but excluded questions relating to pre-pregnancy back pain.

\section{Statistical analysis}

The IBM statistical package, SPSS version 24 (IMB Analytics) was used to analyse the data. A $p$-value of less than 0.05 indicated statistical significance. Descriptive statistics were used to describe the data. All relationships investigated were categorical in nature, thus Chi-square test and or Fischer's exact tests were utilised.

\section{Ethical considerations}

Ethical clearance was given by the Durban University of Technology's Institutional Research Ethics Committee (reference number: REC106/17), eThekwini Health District and KZN Provincial Department of Health prior to commencement of data collection. 


\section{Results}

The mean participant age was $25.8( \pm 6.0)$ with the majority being between 18 and 24 years $(44.6 \%, n=135)$. All participants were black Africans $(n=303)$, with $82 \%$ having a marital status of single $(n=246)$. Unemployment was $70.7 \%$ $(n=212)$, with $77 \%$ of participants having obtained a secondary level of education $(n=228)$. More than half of the participants resided in a town, city or township (54.1\%, $n=160)$, either rented or owned their house and flat $(36.6 \%$, $n=107)$ or lived with a friend or relative $(31.2 \%, n=91)$. The body mass index (BMI) of the women showed that $32.4 \%$ of them $(n=82)$ were overweight and $26.9 \%$ of them $(n=68)$ were obese. Furthermore, $38.7 \%$ were nulliparous $(n=98)$ and $51.2 \%$ were multigravida $(n=155)$. Of the total 303 recruited, only 47 women returned to the clinic at trimester three for continued antenatal care.

Back pain prevalence was reported pre-pregnancy as $5.6 \%$ $(n=17)$, this increased to $12.4 \%(n=35)$ at the first antenatal

TABLE 1: Location, duration, severity and impact of back pain in the first and third trimester.

\begin{tabular}{|c|c|c|c|c|c|c|c|c|}
\hline \multirow[t]{3}{*}{ Variables } & \multicolumn{6}{|c|}{ First antenatal visit } & \multirow{2}{*}{\multicolumn{2}{|c|}{$\begin{array}{c}\text { Third trimester visit } \\
\text { LBP } \\
(n=5)\end{array}$}} \\
\hline & \multicolumn{2}{|c|}{$\begin{array}{c}\mathrm{NP} \\
(n=8)\end{array}$} & \multicolumn{2}{|c|}{$\begin{array}{l}\text { M/UBP } \\
(n=14)\end{array}$} & \multicolumn{2}{|c|}{$\begin{array}{c}\text { LBP } \\
(n=24)\end{array}$} & & \\
\hline & $n$ & $\%$ & $\bar{n}$ & $\%$ & $n$ & $\%$ & $n$ & $\%$ \\
\hline \multicolumn{9}{|c|}{ Duration $(n=7)$} \\
\hline$<2$ weeks & 1 & 14.3 & 6 & 66.7 & 7 & 41.2 & - & - \\
\hline 3-8 weeks & 3 & 42.9 & 1 & 11.1 & 3 & 17.6 & - & - \\
\hline $3-6$ months & - & - & - & - & 2 & 11.8 & 2 & 66.7 \\
\hline$>6$ months & 3 & 42.9 & 2 & 22.2 & 5 & 29.4 & 1 & 33.3 \\
\hline \multicolumn{9}{|c|}{ Severity $(n=7)$} \\
\hline Mild & 3 & 42.9 & 3 & 25.0 & 10 & 47.6 & 2 & 40.0 \\
\hline Moderate & 4 & 57.1 & 7 & 58.3 & 9 & 42.9 & 2 & 40.0 \\
\hline Severe & - & - & 2 & 16.7 & 2 & 9.5 & 1 & 20.0 \\
\hline \multicolumn{9}{|c|}{$\begin{array}{l}\text { Impact on activities } \\
\text { of daily living }(n=7)\end{array}$} \\
\hline Yes & 3 & 42.9 & 5 & 45.5 & 6 & 31.6 & 2 & 40.0 \\
\hline No & 4 & 57.1 & 6 & 54.5 & 13 & 68.4 & 3 & 60.0 \\
\hline
\end{tabular}

$\mathrm{NP}$, neck pain; M/UBP, mid/upper back pain; LBP, low back pain. visit $(n=283)$, with $10.9 \%(n=5)$ reporting suffering back pain at the third trimester visit $(n=47)$. At the first antenatal visit, the most common area affected was the low back pain (LBP), with the majority reporting that the pain started within 2 weeks of the first antenatal visit $(41.2 \%, n=7)$. The pain was described as mild in nature $(47.6 \%, n=10)$ and that it had little impact on their activities of daily living $(54.6 \%, n=6)$. At the third trimester, the participants reported experiencing LBP only, of these participants, $66.7 \%(n=2)$ reported that the pain started by the first antenatal visit and they described the pain as mild to moderate. In addition, $40 \%(n=2)$ of those who suffered LBP in the third trimester indicated that it affected their activities of daily living (Table 1).

Many of the respondents partook in daily activities such as carrying water $(30 \%, n=88)$ and house work $(73 \% ; n=214)$ with very few doing manual labour $(7.2 \%, n=21)$ or gardening $(4.4 \%, n=13)$. The only activity of daily living that was associated with back pain pre-pregnancy $(p<0.001)$ and at the first antenatal visit $(p=0.009)$ was carrying water (Table 2).

Participants were asked, at the first antenatal and third trimester visit, about the impact of their back pain, on their ability to socialise, their frame of mind, the ability to cope with the pain and if the pain raised enough concern for them to seek treatment. The majority of the participants, at the first antenatal visit reported that the back pain had little impact on their lives (Table 3), whereas those returning for the third trimester visit showed a decreased ability to cope with the pain $(57.9 \%, n=11)$. However, only one person sought treatment $(7.1 \%)$.

No significant relationships were found between back pain prevalence and socio-demographic characteristics of the participants except for their type of accommodation. Staying in a hostel or at an employee's property was

TABLE 2: Activities of daily living and back pain prevalence.

\begin{tabular}{|c|c|c|c|c|c|c|c|c|c|c|c|c|c|c|c|c|c|c|c|c|c|}
\hline \multirow[t]{3}{*}{ Variables } & \multicolumn{21}{|c|}{ Back pain prevalence } \\
\hline & \multicolumn{7}{|c|}{ Pre-pregnancy } & \multicolumn{7}{|c|}{ First antenatal visit } & \multicolumn{7}{|c|}{ Third trimester visit } \\
\hline & Total & $\%$ & Yes & $\%$ & No & $\%$ & $p$ & Total & $\%$ & Yes & $\%$ & No & $\%$ & $p$ & Total & $\%$ & Yes & $\%$ & No & $\%$ & $p$ \\
\hline \multicolumn{22}{|c|}{ Carry water } \\
\hline Yes & 88 & 30.0 & 13 & 30.0 & 75 & 25.6 & $0.001 *$ & 83 & 29.7 & 17 & 6.1 & 66 & 23.7 & 0.009 & 14 & 32.6 & 1 & 2.3 & 13 & 30.2 & 1.000 \\
\hline No & 205 & 70.0 & 3 & 1.0 & 202 & 68.9 & & 196 & 70.3 & 17 & 6.1 & 179 & 64.2 & & 29 & 67.4 & 4 & 9.3 & 25 & 58.1 & \\
\hline Total & 293 & 100.0 & 16 & 5.5 & 277 & 94.5 & & 279 & 100.0 & 34 & 12.2 & 245 & 87.8 & & 43 & 100.0 & 5 & 11.6 & 38 & 88.4 & \\
\hline \multicolumn{22}{|l|}{ Gardening } \\
\hline Yes & 13 & 4.4 & 0 & 0.0 & 13 & 4.4 & 1.000 & 12 & 4.3 & 1 & 0.4 & 11 & 3.9 & 1.000 & 2 & 4.7 & 0 & 0.0 & 2 & 4.7 & 1.000 \\
\hline No & 280 & 95.6 & 16 & 5.5 & 264 & 90.1 & & 267 & 95.7 & 33 & 11.8 & 234 & 83.9 & & 41 & 95.3 & 5 & 11.6 & 36 & 83.7 & \\
\hline Total & 293 & 100.0 & 16 & 5.5 & 277 & 94.5 & & 279 & 100.0 & 34 & 12.2 & 245 & 87.8 & & 43 & 100.0 & 5 & 11.6 & 38 & 88.4 & \\
\hline \multicolumn{22}{|c|}{ House work } \\
\hline Yes & 214 & 73.0 & 9 & 3.1 & 205 & 70.0 & 0.147 & 200 & 71.7 & 22 & 7.9 & 178 & 63.8 & 0.416 & 33 & 76.7 & 4 & 9.3 & 29 & 67.4 & 1.000 \\
\hline No & 79 & 27.0 & 7 & 2.4 & 72 & 24.6 & & 79 & 28.3 & 12 & 4.3 & 67 & 24.0 & & 10 & 23.3 & 1 & 2.3 & 9 & 20.9 & \\
\hline Total & 293 & 100.0 & 16 & 5.5 & 277 & 94.5 & & 279 & 100.0 & 34 & 12.2 & 245 & 87.8 & & 43 & 100.0 & 5 & 11.6 & 38 & 88.4 & \\
\hline \multicolumn{22}{|c|}{ Manual labour } \\
\hline Yes & 21 & 7.2 & 2 & 0.7 & 19 & 6.5 & 0.321 & 19 & 6.8 & 2 & 0.7 & 17 & 6.1 & 1.000 & 3 & 7.0 & 0 & 0.0 & 3 & 7.0 & 1.000 \\
\hline No & 272 & 92.8 & 14 & 4.8 & 258 & 88.1 & & 260 & 93.2 & 32 & 11.5 & 228 & 81.7 & & 40 & 93.0 & 5 & 11.6 & 35 & 81.4 & \\
\hline Total & 293 & 100.0 & 16 & 5.5 & 277 & 94.5 & & 279 & 100.0 & 34 & 12.2 & 245 & 87.8 & & 43 & 100.0 & 5 & 11.6 & 38 & 88.4 & \\
\hline
\end{tabular}

$*, p \leq 0.05$ 
TABLE 3: Impact of back pain on the participants as reported at the first and third trimester visits.

\begin{tabular}{|c|c|c|c|c|}
\hline \multirow[t]{2}{*}{ Question } & \multicolumn{2}{|c|}{ First trimester } & \multicolumn{2}{|c|}{ Third trimester } \\
\hline & $n$ & $\%$ & $n$ & $\%$ \\
\hline \multicolumn{5}{|c|}{$\begin{array}{l}\text { Pain prevented spending time with family } \\
\text { and friends }\end{array}$} \\
\hline Yes & 13 & 19.4 & 3 & 14.3 \\
\hline No & 54 & 80.6 & 18 & 85.7 \\
\hline \multicolumn{5}{|c|}{ Pain made me concerned about health } \\
\hline Yes & 27 & 40.3 & 7 & 35 \\
\hline No & 40 & 59.7 & 13 & 65 \\
\hline \multicolumn{5}{|c|}{ Pain made me feel sad or depressed } \\
\hline Yes & 20 & 29.9 & 4 & 21.1 \\
\hline No & 47 & 70.1 & 15 & 78.9 \\
\hline \multicolumn{5}{|c|}{ I am able to cope with the pain } \\
\hline Yes & 53 & 80.3 & 8 & 42.1 \\
\hline No & 13 & 19.7 & 11 & 57.9 \\
\hline \multicolumn{5}{|c|}{ I sought treatment for the pain } \\
\hline Yes & 21 & 31.3 & 1 & 7.1 \\
\hline No & 46 & 68.7 & 13 & 92.9 \\
\hline
\end{tabular}

associated with pre-pregnancy back pain $(p=0.030)$, whilst being single was associated with less risk for developing back pain ( $p=0.018$; odds ratio [OR] $=0.437$; CI: $0.233-0.820$ ) (Table 4).

\section{Discussion}

It is estimated that the majority of women will experience some degree of MSK discomfort during pregnancy, of which back pain is most prevalent (Jimoh et al. 2013). Pregnancyrelated back pain ranges from $25 \%$ to $90 \%$, with more than $50 \%$ of pregnant women suffering with LBP (Wang et al. 2004). Studies in Sub-Saharan Africa are lacking in terms of describing back pain in pregnant women, especially in SA. Our study revealed a low prevalence of back pain in the first $(12.4 \%)$ and third $(11.1 \%)$ trimesters of pregnancy. This is in contrast to studies conducted in other developing countries such as India (Usman et al. 2017) and Ethiopia (Abebe et al. 2014), where back pain prevalence was $34.3 \%$ and $33.2 \%$, respectively. Many factors can influence the prevalence of pregnancy-related back pain. The participants in this study were mostly young Black females experiencing their first pregnancy.

Half of the participants (50.2\%) in this study were below the age of 24. Early childbearing is common in SA with a high prevalence of teenage pregnancies (Panday et al. 2009). In non-pregnant populations, back pain prevalence increases from the third decade (Hoy et al. 2012), yet in pregnancy, the relationship between age and back pain is inconclusive. Our study similar to the study by Abebe et al. (2014) found no relationship between pregnancy-related back pain and age. The marital status of the respondents indicated that most females were single $(81.5 \%)$. Being separated, divorced or widowed has been associated with a higher incidence of back pain possibly because of a lack of support. Being married increases social support, has health benefits and decreases stress with regard to social, financial and living situations (Reblin \& Uchino 2008). Although the respondents in this study were mostly single, many $(31.2 \%)$ resided with a friend or relative who could offer social and financial support because of shared living expenses.

The participants in this study consulted a PHC clinic in a resource poor setting. A lack of education, low income, unemployment and disadvantaged living areas have been reported to predispose females to back pain (Silva et al. 2008). In this study, however, no associations between these variables and back pain prevalence were found, irrespective of the trimester. Low socio-economic status and education are often associated with strenuous work activities (Charpentier et al. 2012). Many of the participants in this study engaged in carrying water (30\%) and doing housework $(73 \%)$. Tasks like carrying water can lead to strain on the body resulting in pain (Geere et al. 2018). Results of this study support this finding, as carrying water was the only common activity of daily living that was associated with back pain. In $80 \%$ of households where there is no access to water on the property, women and girls are responsible for its collection (United Nations 2019). Crucial household tasks need to be met daily, irrespective of whether or not a woman is pregnant. The characteristics of daily activities and their contribution to MSK disorders, especially back pain are not well-documented (BeaucageGauvreau et al. 2012) and in developing countries where these activities are carried out in combination, a cumulative burden may exist.

Some studies suggest that there is an association amongst back pain in pregnancy, parity and gravida (Mogren \& Pohjanen 2005; Mohseni-Bandpei et al. 2009; Mota et al. 2015), our data report no associations as most participants reported this pregnancy as their first pregnancy (38.7\%). Obesity has been associated as a predictor of chronic widespread MSK pain (Heuch et al. 2013), and there is a global increase in obesity prevalence, especially in SA. Notably, $59.3 \%$ of our participants were identified as being overweight. An earlier study suggest that pregnant women with back pain have a higher BMI compared to those without back pain (Mogren \& Pohjanen 2005), however, our data demonstrate no association between BMI and back pain prevalence.

The most common spinal pain experienced by the participants was LBP, similar to other studies (Gorginzadeh, Imani \& Safari 2016; Mota et al. 2015; Ramachandra et al. 2015; Sencan et al. 2017). At the first antenatal visit, those respondents experiencing neck and upper or mid back pain reported it to be acute and sub-acute, whilst in contrast to those with LBP reported a more chronic nature to their pain. On an average, the pain was rated as mild to moderate, with less than half reporting that it impacted their activities of daily living. The majority of pregnant women do not seek medical advice for back pain until it interferes with their daily activities (Ramachandra et al. 2015). It is often seen as an inevitable part of pregnancy (Stuber \& Smith 2008). This is supported by Usman et al. (2017) who suggested that only a small percentage of pregnant women experienced severe back pain. Back pain is often more common in the latter part of pregnancy 


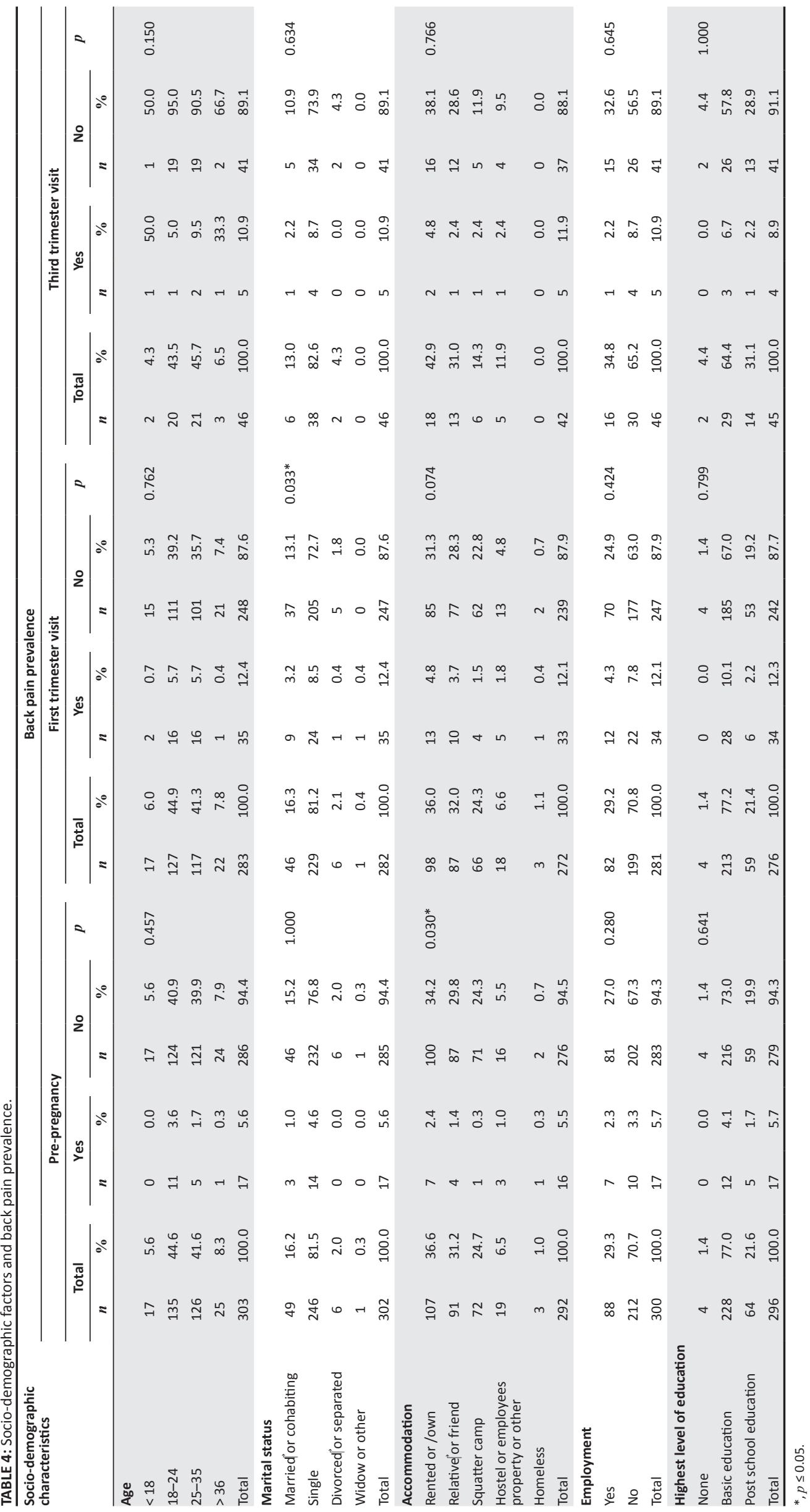


as changes from pregnancy become more pronounced. In this study, $57.9 \%$ of women in the third trimester reported that they were unable to cope with the pain compared to only $19.7 \%$ at the first antenatal visit. Care should be taken in this interpretation because of the low number of women who partook in the third trimester, it does, however, highlight the negative impact back pain can have in pregnancy.

The low return rate $(15 \%)$ of participants to the clinic for their third trimester visit shows the difficulty in performing pregnancy cohorts in developing countries. Women come to the city to work, fall pregnant and then return to the rural farm areas to deliver their babies. This impacts the ability to track the cohort through the gestational period. Access to adequate ANC care has been a strategy to address the fourth Millennium Development Goal to reduce child mortality. ANC care in developing countries has a major focus on reducing pregnancy-related mortality and morbidity, taking measures to make the gestational period as tolerable as possible for mothers and their families (Gorginzadeh et al. 2016). South Africa has made significant progress with regard to the improvement of maternal health and the reduction of maternal mortality in the last two decades (National Department of Health, Statistics SA, South African Medical Research Council \& ICF 2017), yet more work is required.

Current management at PHC levels in SA has been ineffective with no conformity to guidelines (Major-Helsloot et al. 2014). This is one of the first studies, to our knowledge, that has investigated back pain in a pregnant cohort in SA. Despite the low prevalence of back pain in these pregnant women from a resource poor setting, further studies are necessary in similar and different contexts within SA to determine the impact of back pain in pregnancy and to assess other factors such as exercise.

\section{Conclusion}

This study showed a low prevalence of back pain in pregnancy in a South African cohort of women attending a public ANC in a resource poor setting. As pregnancy duration increased, the ability to cope with the back pain decreased, highlighting that even if the prevalence is low, the disability for those who suffer from back pain in pregnancy is great.

\section{Acknowledgements}

The authors would like to acknowledge C. W. Nare, C. Singh and D. Rajpal for their administration of the project and the nursing staff at the PHC. The authors would like to thank the study participants for giving their time to complete the surveys.

\section{Competing interests}

The authors declare no competing interests, financial or personal relationship that may have inappropriately influenced them in writing this manuscript.

\section{Authors' contributions}

C.H., L.O'C., P.R., F.H., M.N.S., D.B., S.G., T.S.P.N. and N.G. all contributed to this research in terms of the criteria for authorship as outlined in the authorship policy and author contribution statement policies.

\section{Funding information}

The research was funded by the South African Medical Research Council (grant number DUT/MH1).

\section{Data availability}

De-identified data will be made available on request through application to Prof M. N. Sibiya,nokuthulas@dut.ac.za.

\section{Disclaimer}

The views expressed in this article are those of the authors and are not an official position of the institution or funder.

\section{References}

Abebe, E., Singh, K., Adefires, M., Abraha, M., Gebremichael, H. \& Krishnan, R., 2014 'History of low back pain during previous pregnancy had an effect on development of low back pain in current pregnancy attending antenatal care clinic of University
of Gondar hospital, Northwest Ethiopia', Research and Reviews: Journal of of Gondar hospital, Northwest Ethiopia', R
Medical Science and Technology 3(3), 37-44.

Ayanniyi, O., Sanya, A.O., Ogunlade, S.O. \& Oni-Orisan, M.O., 2006, 'Prevalence and pattern of back pain among pregnant women attending ante-natal clinics in pattern of back pain among pregnant women attending ante-natal clinics in
selected health care facilities', African Journal of Biomedical Research $9(3)$, 149-156. https://doi.org/10.4314/ajbr.v9i3.48898

Beaucage-Gauvreau, E., Dumas, G. \& Lawani, M., 2012, 'Trunk postural demands of occupational activities of some merchant pregnant women in Benin, West Africa', Ergonomics 55(10), 1218-1228. https://doi.org/10.1080/00140139.2012.702790

Benatar, S., 2013 'The challenges of health disparities in South Africa', South African Medical Journal 103(3), 154-155. https://doi.org/10.7196/SAMJ.6622

Bergström, C., Persson, M. \& Mogren, I., 2016, 'Sick leave and healthcare utilisation in women reporting pregnancy related low back pain and/or pelvic girdle pain at 14 months postpartum', Chiropractic and Manual Therapies 24(1), 7. https://doi. org/10.1186/s12998-016-0088-9

Bolton, J.E. \& Breen, A.C., 1999, 'The Bournemouth Questionnaire: A short-form comprehensive outcome measure. I. Psychometric properties in back pain patients', Journal of Manipulative Physiological Therapeutics 22(8), 503-510. https://doi.org/10.1016/s0161-4754(99)70001-1

Charpentier, K., Leboucher, J., Lawani, M., Toumi, H., Dumas, G.A. \& Pinti, A., 2012, 'Back pain during pregnancy and living conditions - A comparison between Beninese and Canadian women', Annals of Physical and Rehabilitation Medicine 55(3), 148-159. https://doi.org/10.1016/j.rehab.2012.02.003

Crawford, O.J., 2007, 'The Nordic Musculoskeletal Questionnaire', Occupational Medicine 57(4), 300-301. https://doi.org/10.1093/occmed/kqm036

Docking, R., Fleming, J., Brayne, C., Zhao, J., Macfarlane, G., Jones, G. on behalf of the Cambridge City over-75s Cohort Study Collaboration, 2011, 'Epidemiology of back pain in older adults: Prevalence and risk factors for back pain onset', Rheumatology 50(9), 1645-1653. https://doi.org/10.1093/rheumatology/ker175

Dungumaro, E.W., 2008, 'Gender differentials in household structure and socioeconomic characteristics in South Africa', Journal of Comparative Family Studies, Calgary 39(4), 429-451. https://doi.org/10.3138/jcfs.39.4.429

Fowkes, F.J.I., Draper, B.L., Hellard, M. \& Stoové, M., 2016, 'Achieving development goals for HIV, tuberculosis and malaria in sub-Saharan Africa through integrated antenatal care: Barriers and challenges', BMC Medicine 14, 202. https://doi. org/10.1186/s12916-016-0753-9

Gorginzadeh, M., Imani, F. \& Safari, S., 2016, 'Pregnancy-related pelvic pain: A neglected field in developing countries', Anesthesiology and Pain Medicine 6(1) e35506. https://doi.org/10.5812/aapm.35506

Geere, J.A., Bartram, J., Bates, L., Danquah, L., Evans, B., Fisher, M.B. et al., 2018, 'Carrying water may be a major contributor to disability from musculoskeletal disorders in low income countries: A cross-sectional survey in South Africa, Ghana and Vietnam', Journal of Global Health 8(1), 010406. https://doi.org/10.7189/ jogh.08.010406

Heuch, I., Heuch, I., Hagen, K. \& Zwart, J., 2013, 'Body mass index as a risk factor for developing chronic low back pain: A follow-up in the Nord-Trøndelag Health Study', Spine 38(2), 133-139. https://doi.org/10.1097/BRS.0b013e3182647af2

Hoy, D., Bain, C., Williams, G., March, L., Brooks, P., Blyth, F. et al., 2012, 'A systematic review of the global prevalence of low back pain', Arthritis \& Rheumatism 64(6), 2028-2037. https://doi.org/10.1002/art.34347@ 
Jimoh, A., Omokanye, L., Salaudeen, A., Saka, M., Akinwale, A., Balogun, O. et al. 2013 'Prevalence of low back pain among pregnant women in llorin, Nigeria', Academic Journals 4(4), 23-26. https://doi.org/10.5897/MPR12.014

Kristiansson, P., Svärdsudd, K. \& Von Schoultz, B., 1996, 'Back pain during pregnancy: A prospective study', Spine (Phila Pa 1976) 15 21(6), 702-709. https://doi. org/10.1097/00007632-199603150-00008

Major-Helsloot, M., Crous, L.C., Grimmer-Somers, K. \& Louw, Q., 2014, 'Management of LBP at primary care level in South Africa: Up to standards?', African Health Sciences 14(3), 698-706. https://doi.org/10.4314/ahs.v14i3.28

Mogren, I. \& Pohjanen, A., 2005, 'Low back pain and pelvic pain during pregnancy: Prevalence and risk factors', Spine 30(8), 983-991. https://doi.org/10.1097/01. brs.0000158957.42198.8e

Mohseni-Bandpei, M.A., Fakhri, M., Ahmad-Shirvani, M., Bagheri-Nessami, M., Reza Khalilian, A., Shayesteh-Azar, M. et al. 2009, 'Low back pain in 1100 Iranian pregnant women: Prevalence and risk factors', The Spine Journal 9(10), 795-801. https://doi.org/10.1016/j.spinee.2009.05.012

Mota, M.J., Cardoso, M., Carvalho, A., Marques, A., Sá-Couto, P. \& Demain, S., 2015 'Women's experiences of low back pain during pregnancy', Journal of Back Musculoskeletal Rehabilitation 28(2), 351-357. https://doi.org/10.3233/BMR140527

Napier, C., Oldewage-Theron, W. \& Kearney, J., 2009, 'Comparison of three schoo feeding strategies for primary school children in an informal settlement in Gauteng, South Africa', Health SA Gesondheid 14(1), 1-8. https://doi.org/10.4102/ hsag.v14i1.458

National Department of Health (NDoH), Statistics South Africa (Stats SA), South African Medical Research Council (SAMRC) \& ICF, 2017, South Africa demographic and health survey 2016. Key indicators, NDoH, Stats SA, SAMRC and ICF, Pretoria.

Panday, S., Makiwane, M., Ranchod, C., \& Letsoalo, T., 2009, Teenage pregnancy in South Africa - with a specific focus on school-going learners, Child, Youth, Family and Social Development, Human Sciences Research Council, Department of Basic Education South Africa, Pretoria.

Quaresma, C., Silva, C., Forjaz Secca, M., Goyri O'Neill, J. \& Branco, J., 2010, 'Back pain during pregnancy: A longitudinal study', Acta Reumatologica Portuguesa 35(3), 346-351.
Ramachandra, P., Maiya, A.G., Kumar, P. \& Kamath, A., 2015, 'Prevalence of musculoskeletal dysfunctions among Indian pregnant women', Journal of Pregnancy 2015, Article ID 437105, 1-4. https://doi.org/10.1155/2015/437105

Reblin, M. \& Uchino, B., 2008, 'Social and emotional support and its implication for health', Current Opinion in Psychiatry 21(2), 201-205. https://doi.org/10.1097/ YCO.0b013e3282f3ad89

Sencan, S., Ozcan-Eksi, E.E., Cuce, I., Guzel, S. \& Erdem, B., 2017, 'Pregnancy-related low back pain in women in Turkey: Prevalence and risk factors', Annals of Physical and Rehabilitation Medicine 61(1), 33-37. https://doi.org/10.1016/j.rehab.2017.09.005

Silva, L., Coolman, M., Steegers, E., Jaddoe, V., Moll, H., Hofman, A. et al., 2008, 'Low socioeconomic status is a risk factor for preeclampsia: The generation R study', Journa of Hypertension 26(6), 1200-1208. https://doi.org/10.1097/HJH.0b013e3282fcc36e

Skaggs, C.D., Prather, H., Gross, G., George, J.W., Thompson, P.A. \& Nelson, D.M., 2007 'Back and pelvic pain in an underserved United States pregnant population: A preliminary descriptive survey', Journal of Manipulative Physiological Therapeutics 30(2), 130-134. https://doi.org/10.1016/j.jmpt.2006.12.008

Statistics South Africa, 2011, Census 2011: Census in brief, viewed 02 June 2020, from https://www.un.org/sustainabledevelopment/water-and-sanitation/www.statssa. gov.za/census/census_2011/census_products/Census_2011_Census_in_brief.pdf.

Stuber, K.J. \& Smith, D.L., 2008, 'Chiropractic treatment of pregnancy-related low back pain: A systematic review of the evidence', Journal of Manipulative and Physiological Therapeutics 31(6), 447-454. https://doi.org/10.1016/j.jmpt.2008.06.009

United Nations, 2019, Sustainable development goals: Goal 6 ensure access to water and sanitation for all, viewed 29 March 2021, from https://www.un.org/ sustainabledevelopment/water-and-sanitation/.

Usman, M.I., Abubakar, M.K., Muhammad, S., Rabiu, A. \& Garba, I., 2017, 'Low back pain in pregnant women attending antenatal clinic: The Aminu Kano teaching hospital experience', Annals of African Medicine 16(3), 136. https://doi org/10.4103/aam.aam_214_16

Wang, S.M., Dezinno, P., Maranets, I., Berman, M.R., Caldwell-Andrews, A.A. \& Kain, Z.N., 2004, 'Low back pain during pregnancy: Prevalence, risk factors, and outcomes', Obstetrics and Gynaecology 104(1), 65-70. https://doi. and outcomes', Obstetrics and Gynaecolog

Worku, Z., 2000, 'Prevalence of low-back pain in Lesotho mothers', Journal of Manipulative and Physiological Therapeutics 23(3), 147-154. https://doi. org/10.1016/S0161-4754(00)90243-4 